\title{
Value Transformation in Relationship Marketing
}

by Nikolaos Tzokas, Senior Research Fellow and Michael Saren, Professor of Marketing

Department of Marketing, University of Strathclyde

\begin{abstract}
Based on the principle that customer value is a key concept in the marketing discipline, this paper presents a review and critique of current knowledge in this field. It develops the idea that value is located in the competitive and collaborative acts of the consumers and transformed by means of a dialogue in the relationships among the firm and its customers.
\end{abstract}

The paper concludes with a number of suggestions for advancing our understanding of this critical area of the marketing discipline.

\section{Introduction}

Rapid changes in the economic, environmental and corporate context have destabilised key terms in the lexikon of marketing and undermined the prominence of the discipline in the market place. Recipes of the past do not seem to work anymore (McKenna, 1991).

Relationship marketing (RM) is the latest recipe in the quest of firms for competitive advantage in consumer markets. Whilst some authors wonder whether or not this a "flavour-of-the-month" (Barnes, 1994) approach to marketing others seem to agree that RM represents a genuine paradigm shift of marketing, from an exchange, transactional focus to one in favour of the relationship between the supplier and its customer(s) (Sheth and Parvatiyar, 1995). Yet, others maintain that "the complexity and flux of todays competitive environment appears to have rendered marketing mutant and unable to adapt" (Brown, 1995, p.53).

Although the new concept has been received enthusiastically, both marketers and academics seem unable to agree on its content and boundaries. Academics find their examples of excellent relationship practices rejected in the market place, like IBM has found that reliability and after sales service cannot be the relationship and value proposition of the past as most of the computers components are highly standardised today and Volvo painfully realised in its previous marketing campaign that safety and reliability without fun is not attractive at all. After all who wants to be in a cage even if "cages save lives" (previous advertising campaign of Volvo).

As a result marketing is currently finding itself in the "scapegoats" corner of the corporate failure and paradoxically is held responsible for not delivering that which can not be delivered by one function alone. Attempts to fight back and live up to the promises made 40 years ago are highly visible in the last decade and at present. These efforts comprise two directions. 
One involves attempts to lessen the popular belief that marketing alone can bring business and product success in the market place. Here, there is a call for allowing the basic marketing principle of customer focus to permeate all levels of the organisation. In Gummessons (1987) own words "everyone is a part-time marketer". As such, success is viable by means of integrating and co-ordinating all the activities of the firm and by instigating a clear customer focus to the firm. Responsibility for understanding customers and contributing to the delivery of value to them is charged to all members of the organisation rather than to marketing only (see for example, Webster 1988).

Value is a cornerstone concept in the marketing discipline. There is wide agreement that the raison detre of marketing is to assist the firm to create value for its customers that is superior to competition. It can be reasonably argued that a key line for defending Marketings role in the organisation is that it supports the view that unless value is created and delivered to customers neither the firm has a legitimate reason to exist nor it can accomplish its corporate objectives. In the early days of Marketing, the above argument or philosophy was defensible, in the sense that it was sufficiently different from that advocated by other constituencies seeking to maintain their role primacy within the organisation.

Nevertheless, despite its importance for the marketing discipline, little research effort has been devoted to examining what this value is, how it is produced, delivered and consumed and how it is perceived by the customer. In addition, this effort primarily has been located in the knowledge pool of areas other than Marketing, e.g. strategy and strategic management, psychology and sociology of consumer behaviour, accounting and finance. Based on these works, the value concept has become a flagship of every constituency of the firm and any contemporary organisation as a whole. While this is gratifying for Marketing, it has nevertheless diluted the uniqueness of its defensive position. The latter, in conjunction with the relative lack of research in the mainstream marketing field, has undermined severely Marketings ability to advocate its essential role in the whole process of value creation and delivery.

Acknowledging the need for additional insight in the process of value creation and delivery, the second of the above directions involves efforts to conceptualise and measure what the value concept is for the customer and how it can be produced and delivered by the firm.

\section{The value concept}

It is really pleasing to report here that in our efforts to review existing literature on the concept of value we came across one of the best works in the field by Wilson in Jantrania (1994) which was presented in the first International Colloquium in Relationship Marketing (see Table 1). These authors have presented an excellent review of the ways value is used/measured across a number of disciplines including accounting and finance, purchasing and materials management, economics and marketing. 
The many "faces" of value

\begin{tabular}{|c|c|c|c|}
\hline \multicolumn{4}{|c|}{ Use of value in a number of disciplines } \\
\hline $\begin{array}{l}\text { Accounting and } \\
\text { Finance }\end{array}$ & Economics & $\begin{array}{l}\text { Purchasing and } \\
\text { Materials Management }\end{array}$ & Marketing \\
\hline $\begin{array}{l}\text { Recorded Value } \\
\text { Market Value } \\
\text { Replacement } \\
\text { Value } \\
\text { Assessed Value } \\
\text { Appraised Value } \\
\text { Earning Potential } \\
\text { Liquidation Value }\end{array}$ & $\begin{array}{l}\text { Use Value } \\
\text { Exchange } \\
\text { Value } \\
\text { Cost Value }\end{array}$ & $\begin{array}{l}\text { Use } \\
\text { Esteem Value }\end{array}$ & $\begin{array}{l}\text { Economic value to } \\
\text { customer (EVC) } \\
\text { Value-in-use (VIU) }\end{array}$ \\
\hline
\end{tabular}

\section{Components of Product Value}

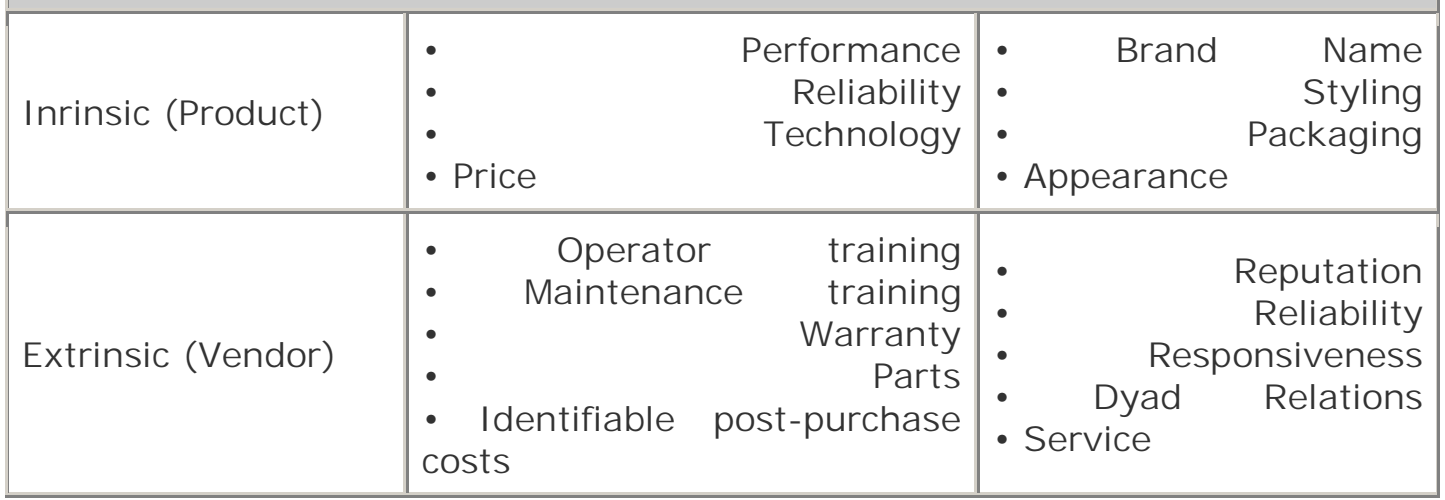

\section{A typology of value in the consumption experience}

\begin{tabular}{|l|l|l|l|}
\hline & & Extrinsic & Intrinsic \\
\hline Self-Oriented & Active & $\begin{array}{l}\text { Efficiency } \\
\text { (O/I ratio or convenience) }\end{array}$ & $\begin{array}{l}\text { Play } \\
\text { (fun) }\end{array}$ \\
\hline \hline Other-Oriented & Reactive & $\begin{array}{l}\text { Excellence } \\
\text { (quality) }\end{array}$ & $\begin{array}{l}\text { Esthetics } \\
\text { (beauty) }\end{array}$ \\
\hline \hline & Reactive & $\begin{array}{l}\text { Esteem } \\
\text { (reputation) }\end{array}$ & $\begin{array}{l}\text { Morality } \\
\text { (virtue or ethical acts) }\end{array}$ \\
\hline
\end{tabular}

Furthermore, they developed their own understanding of what relationship value is and urged for further research on value which according to them is "a problematic concept which cannot be ignored" (p.63). Wilson and Jantrania (1994) suggested that value considered within the context of relationships should be measured in three dimensions namely, economic, strategic and behavioural. While, these dimensions formed a three-dimensional value space, Wilson and 
Jantrania (1994) provided no further explanation as to the interrelationships among these dimensions.

They suggested that "in assessing the value of a relationship we may best begin with economic value. Then we may attempt to evaluate the strategic value created and finally estimate some qualitative estimate of the behavioral elements of the relationship" (p.63). Despite this inherent limitation their work is among the few to consider the concept of value within relationships. Following, we consider three additional pieces of work, which in our opinion have contributed further understanding on the value concept.

First, within a relational marketing context Ravald and Groonros (1996) and Groonros (1997) have proposed ways of measuring "the customer perceived value of an episode or total episode value" and "customer perceived value (CPV)" (Table 2)

Table 2: Total episode value and customer perceived value

$$
\begin{aligned}
& \text { Total episode value }=\frac{\text { Episode benefits }+ \text { relationship benefits }}{\text { Episode sacrifice + relationship sacrifice }} \\
& \text { Customer Perceived Value }(\mathrm{CPV})=\frac{\text { Core solution }+ \text { Additional Services }}{\text { Price }+ \text { Relationships Costs }} \\
& \text { Customer Perceived Value }(\mathrm{CPV})=\text { Core Value }+ \text { or }- \text { Added Value }
\end{aligned}
$$

Ravald and Gronroos (1996) introduced the concept of relationship benefits and sacrifice when calculating the value of an episode within a relationship context. As such a firm can increase the value for the consumer by either reducing the sacrifice (cost efficiency) or increasing the benefits (market efficiency) (see also Wilkstrom and Normann, 1994). These activities are defined as "creating added value by relieving the customer and creating added value by enabling the customer" (p.27).

Elsewhere, Gronroos (1992) defines supplier relationship costs (relationship sacrifice) as direct costs (e.g. insurance premiums, subscription fees etc.), indirect (e.g. delayed delivery, incorrect invoices etc.) and psychological relationship costs (e.g. cognitive effort needed to worry about whether the supplier will fulfil his commitment or not etc.). The importance of these works lie in the fact that they bring into the picture the costs and benefits associated with the relationship itself as determinants of the overall value perceived by the customer. In addition such a treatment of customer perceived value is in line with strategic thinking emanating from Porters (1980) value chain framework in that it allows marketers to think in terms of developing strategies for relieving or enabling the customer. Adding to this strategic dimension, Piercy (1998) provided an analytical framework (see Figure 1) that illustrates how the different dimensions of organisational processes lead to customer value. 
Figure 1: The dimensions of organisational processes

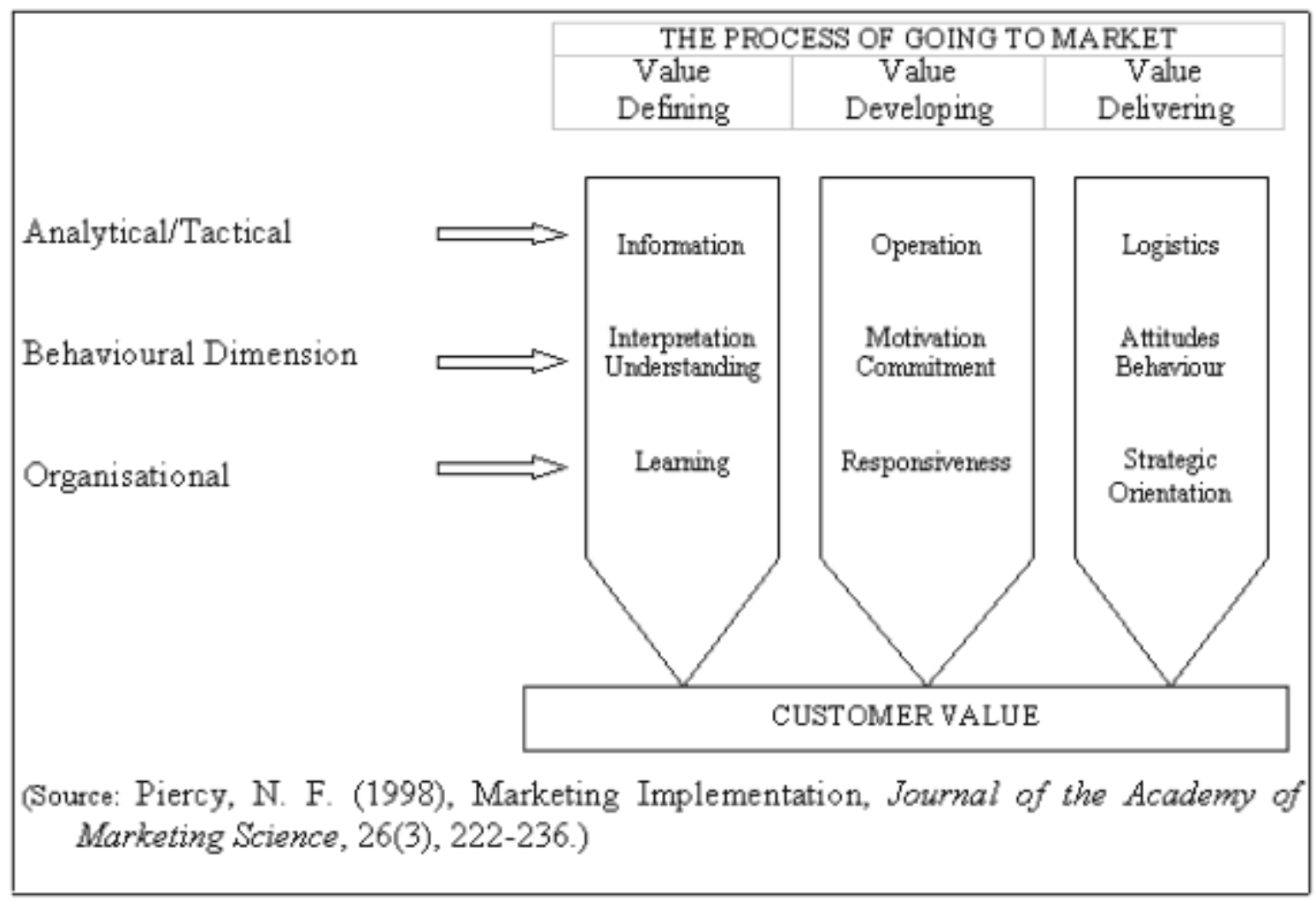

Second, the work by de Ruyter, Wetzels, Lemmink and Mattsson (1997). These authors used a framework for measuring value based on the axiological dimensions of value developed by Hartman (1973) and adapted by Mattsson $(1998,1990)$. More specifically, they used three generic dimensions of value namely, emotional, practical and logical in order to assess customer perceived value at the different stages of the service delivery process within the context of museums.

They found that perceptions of value dimensions as well as overall customer perceived value change depending upon the stage in the value delivery process and the number/sequence of stages performed by the museum visitors (i.e. entrance, temporary collection, permanent collection, restaurant, museum shop and wardrobe). According to the same authors this is a clear indications that an overall score of customer value would be misleading as "the combination of individual service stages has an impact on the effect on overall satisfaction" (p.241). Indeed, museum visitors, like consumers of other goods or services, can follow different routes in their museum visit, thus building their own unique museum consumption experience, which is hard to be pre-determined by marketers. This resonates writings in contemporary consumer research were customer value has been defined as "a relativistic (comparative, personal, situational) preference characterising a subjects experience of interacting with some object" (Holbrook 1994, p.27). Also, it re-enforces the suggestion that consumers play an active role in the construction of their consumption experience thus acting as co-producers of value. Taken one step further, Wikstrom (1996) suggested that "the companys role is no longer limited to supporting the customer by providing goods or services. Rather it is a question of designing a system of activities within which customers can create their own value" (p.360). 
Third, Woodruf (1997), based on a cognitive logic of information processing, developed the concept of customer value hierarchy (see figure 2 ). This model "incorporates both desired and received value and emphasizes that value stems from customers learned perceptions, preferences, and evaluations. It also links together products with use situations and related consequences experienced by goal-oriented customers" (p.142). In addition, Woodruf (1997) and Flint at al. (1997) outlined the dynamic nature of customer value and presented a number of trigger events which can change customers perception of value. In a commentary of the Woodruf (1997) article, Parasuraman (1997) postulated that "as customers move from being first-time to short-term to long-term customers, their value assessment criteria may become increasingly global and abstract. First-time customers will likely focus primarily on attribute-level criteria, but short- and long-term customers will likely focus on consequence- and goal-level criteria" (p.157). Despite the fact that Woodrufs model is open to criticism mainly because of its foundations in cognitive theory (see Shanteau, 1992; Spence and Brucks, 1997) it nevertheless provides useful new avenues for leveraging customer value. The time perspective explicit in Woodrufs model combined with the earlier reviewed work of de Ruyter et al. (1997) suggest that a better understanding of customer value will be gained if value is addressed at different levels of the consumption experience with the product itself and at different stages of the relationship with the firm (supplier).

Figure 2: Customer value hierarchy model.

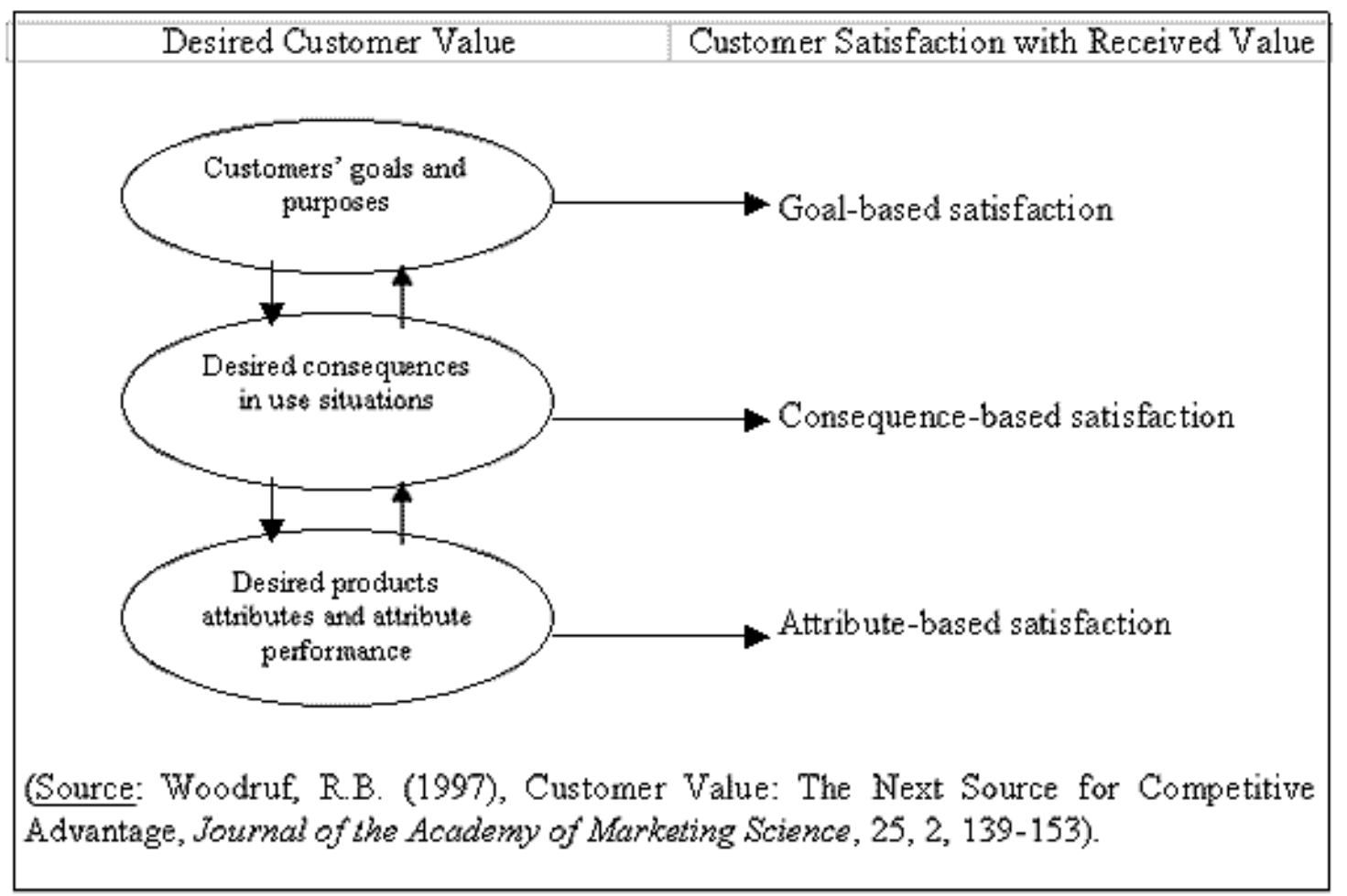

Overall, literature reviewed above presents the state-of-the-art of contemporary knowledge about customer value. By all accounts this is quite limited knowledge. According to Woodruf (1997) "we need richer customer value theory that delves deeply into the customers world of product use in their situations" (p.150). The same author urges for more research into tools that can be used by management to better understand what customer value is and how it can be translated into managerial processes and practices. 
In our opinion the dearth of knowledge in this critical area of marketing and organisational activity can be attributed to the following deficiencies.

First, the vast majority of research into customer value represents efforts to measure a hypothetical and as yet ill understood concept. Yet, measures of customer value are simply low operational variables, whereas value is a higher level hypothetical construct and it should be acknowledged that between the two lies a system of intervening variables. The latter is illustrated graphically in the following figure 3 .

Figure 3: Encounters and Customer value

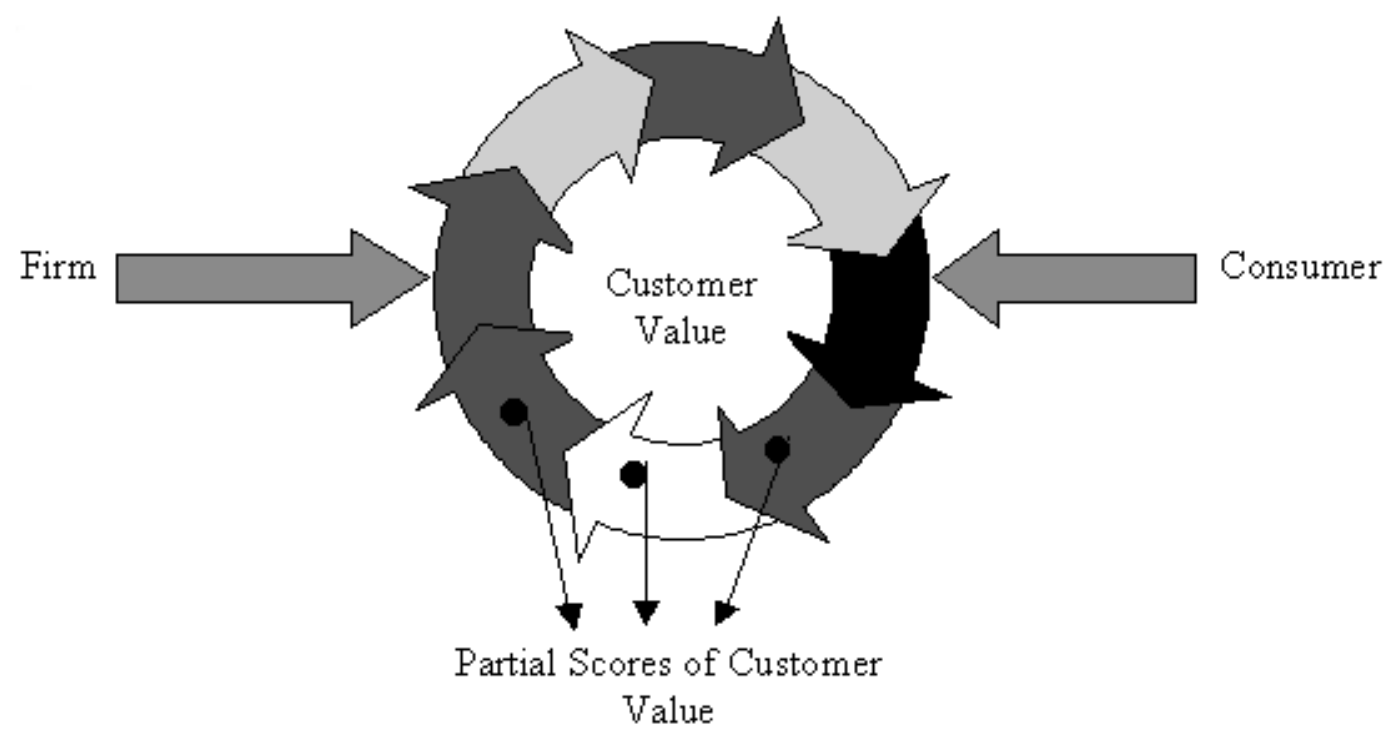

Using an analogy from the physical sciences, one should acknowledge that snapshot measurement of the neutrons can not provide a reliable measurement of the mass, as it is the continuous movement and interaction of these particles that distort any notion of final mass. Similarly, in our case the continuous interplay/interaction between the firm and a customer transforms value into an inherently dynamic concept. Therefore, measurements of customer value are only snapshot and partial scores of a higher level construct. This is reminiscent of criticism in another important field of marketing activity i.e. service quality. After many debates on the usefulness of the SERVQUAL instrument (Parasuraman et al., 1985, 1988; Cronin and Taylor, 1992) it was acknowledged that the instrument assessed what customers attribute to a service of high quality but not their attributions. As a response Bitner $(1990,1992)$ and Zeithaml, Berry and Parasuraman (1993) put forward very interesting conceptual frameworks for investigating the nature and determinants of customer expectations in services. In a similar vein, we need to address customers attributions to value rather than simply seeking what they attribute to it (see Heider 1953).

Secondly, we join voices with Gummesson (1998) who attributes problems encountered in the field of customer value to the fact that "production is viewed as value creation or value added by the supplier, whereas consumption is value depletion caused by the customer. If the consumer is the focal point of marketing, however, value creation is only possible when a product or service is consumed. An unsold product has no value, and a service provider without customers cannot produce anything" (p.246). Indeed, the traditional view of 
value creation in marketing models has assumed that value is created by organisational processes within firms and is progressively build up through exchange and competition among firms or systems of firms. Marketing theory argues that a firm creates value essentially through two core elements. One, a customer focus, whereby the objective of the firm is to identify and serve the needs of the customers profitably, by placing them as the primary interest over and above all other competing claims on the firms resources. Second, a competitive orientation, whereby the firm aims to develop and maintain a competitive advantage over other firms.

However, as it has been eloquently articulated by Day and Wensley, (1983) "a customer orientation implies a battle for ultimate customers that is won by direct appeal to these customers?.By contrast a competitive orientation views customers as an ultimate prize gained at the expense of rivals in many ways other than by simply offering a better match of products to customer needs" (p.82). In both cases the customer becomes a prize and is detached from the value creation process.

A number of writers in the relationship marketing stream have already begun to take a contrary view of the value creation process whereby value is co-created by the firm and the customer/consumer (Normann and Ramirez, 1993; Wikstrom, 1996). Tzokas and Saren (1997) went further and postulated that the value creation process is incomplete without the consumers active involvement and indeed the consumer not the firm is the primer driver of the value creation process. However, the same authors noticed that the "current invitation to customers for joint value creation, as a co-producer, is limited to the characteristics of the product/service and constitutes a myopic view of the customers productive means and capabilities. Customers are invited to join the value chain of the firm productively but the means offered to them are supplier specific" (p.111). This is, consumers are asked to join the firms value chain, without taking account of their own unique means of value creation in the consumers own domain. This contributes a gap in relationship marketing theory, which needs to be addressed.

In order to tackle the above deficiencies we suggest that, among other things, two key concepts need to be explored. First, the idea that consumers create value in the market place by means of the competitive and collaborative acts in which they engage with each other. Secondly, the idea that a dialogue among the firm and its customers is capable of revealing the attributions of customer perceptions of value to the firm. We take on each of these points in the following parts of this paper.

\section{Consumers creation of value through competition and collaboration}

We propose that the principle role of consumption, that is, the activities, behaviours and motivations that consumers undertake when making decisions and forming perceptions about products and services, can be most effectively conceptualised as an expression of value creation. Marketing theory has applied several models to understand the motivations and intentions underlying consumers behaviour. Until recently, the dominant view of the consumer relied upon economic assumptions of need satisfaction and rational decision making (Engel et al, 1990), and it is evident in the previously reviewed notions of customer value. This view, however, has gradually lost mass support to alternative views grounded in anthropology, cultural studies and social theory. 
Rather than being understood as a goal orientated, utility seeking decision maker, the consumer is represented as having many different motives, behaviours and agendas. Consumption is often an irrational and playful activity involving fantasy and hedonism (Holt, 1995; Hirschman \& Holbrook, 1982). Individuals construct and experience their identity, self and lifestyle through consumption, using it as a complex cultural discourse to maintain and communicate status, social position and taste (Holt, 1998; Belk, 1988). In this context consumer goods together with the rituals, behaviours and exchanges in which they are used, visualise and make stable the categories of culture with which we are familiar (Douglas \& I sherwood, 1996).

The notion that consumer goods are employed to signify social position and used by individuals to compete against one another can hardly be considered a particularly modern or contemporary state of affairs. Several classic anthropological studies have shown that the primary function of material culture is not the satisfaction of needs but the role in social rituals and the establishment of social hierarchies both within and between groups (for example, Mauss, 1966; Malinowski, 1922; Douglas and Isherwood, 1996; Gell, 1986). In many ways, the modern obsession with collecting or amassing certain types of products and goods to signify social prestige and wealth marks western capitalism apart from many other forms of social organisation. In the societies studies by Mauss for example, the social significance of goods arises not from them being displayed by their owner but rather by being given away as gifts to others such at rivals and those with whom one is in competition.

In a more modern western context, Veblen (1899) detailed the conspicuous consumption of the noveau riches, and the manner in which certain types of goods and services (and how they were consumed) became important registers of social position. The success of early department stores as centres for taste and fashion was largely a consequence of the vast appetite for status symbols among this newly emerging affluent middle class (Learmans, 1993; Williams, 1982). Similarly, Bourdieu (1984) considers modern consumption to be primarily involved in the establishment and maintenance of distinction or difference between social classes and status groups. The maintenance of difference thus not only implies a competitive relationship between consumers who perceive themselves to inhabit different groups and identities, but also a collaborative effort. By seeking to join or align themselves with desirable groups individual consumers must collaborate with the other consumers in that group in terms of shared consumption ambitions and intentions, and adopting similar behaviours and lifestyles.

Bourdieu argues that since access to various forms of capital is unequal, those with greater access are able to use this capital to establish difference through exclusive notions of taste and refinement. For the purposes of this discussion it is helpful to return to Tarde (1890/1962) who considered desire to be constituted through the dynamics of social relations governed by the laws of imitation rather than in terms of innate drives. The desire to have or not have can thus be thought to be highly related to what others around us have and do not have.

Though perhaps particularly significant, consumer competition should not only be considered solely in terms of status seeking behaviour or in relation to the conspicuous consumption of certain types of luxury products and services. Consumer competition and collaboration is, first and foremost, concerned with the construction and maintenance of ones identity, that is, the sense in which we as individuals can distinguish ourselves from others on the one hand, and become associated with preferred groups on the other. Every single consumption decision 
represents a fragment of our total personal identity and whilst certain types of consumption encounters may have greater significance in terms of status (a designer suit, knowledge of fine wine or a luxury car for instance), the more mundane and habitual consumption decisions we make constitute how we see ourselves as consumers and individuals in society.

When viewed in this way, consumption decisions can be recontextualised as value creating rather than value acquisition. As an active agent, the consumer is the source at which value is realised and actualised, rather than value being understood as arising from organisational activities and procedures. Different consumers are, after all, likely to have different expectations from similar products because their lifestyles and needs will vary. Consequently, the value that is attached to various products will be ultimately dependent upon the perceptions and expectations of the consumers themselves rather than on organisational definitions and intentions of the value that their products are considered to have. It is perhaps helpful to conceptualise consumption as an active and constructive behaviour (Baudrillard, 1996; Ostergaard et al, 1998) in which consumers build up a profile of products and services which they consider to represent and fulfil there own individual aspirations. The corollary is that consumers, by making discriminatory decisions, also build their identity through the products and services they choose not to associate themselves with.

When taken as individual product choices, the application of this notion of consumer competition and collaboration may appear somewhat overstated. Many products, after all, represent repeat, low involvement purchases and it is possible that consumers think very little about the meaning or significance of any one particular consumption act. If, however, it is taken as but one tiny component in the consumers entire consumption behaviour it becomes possible to view the notion of consumer competition and collaboration in the market place the driving force of the consumers attributions of value in products and services as a realistic and plausible thesis.

\section{On dialogue}

It would be fair to suggest that one of the challenges faced by contemporary organizations has to do with the development of mechanisms to assist organisation-wide learning about their customer base. In our case this can be conceived as organisational learning about how customer perceive or attribute value and their attributions. By all means this entails getting as close as possible to what has been termed as customers experiential space (Vandermerwe, 1996) i.e. the space where customers review, take and retake decisions on their everyday consumption activities, and link them to the subjective construction and improvement of their social identities and personal lives. According to Woodruf (1997) such mechanisms should appreciate that consequences of consumption decisions are "rooted in specific use situations and occasions and tend to be more abstract that attributes?" (p.150). In addition, for this knowledge to become influential in the decision making practices within the organisation, management should strive to move beyond procedural learning to what has been termed deutero learning (Argyris and Schon (1978), Sinkula, 1994).

The marketing research tool-kit consists of a number of quantitative and qualitative techniques for the collection and analysis of customer data. However, in recent years these techniques have been criticized heavily. This criticism revolves around three key themes. First, in many cases, it is difficult for the firm 
to use these techniques; second, customers (respondents) find it difficult to respond meaningfully to the tasks they required to perform and third, these techniques could stifle creativity and entrepreneurship as they favour what is known and of little risk (Zaltman 1996; Brownlie and Saren, 1992; Workman, 1993).

We would add to this list, that these techniques in marketing have been developed under the assumption that the different actors in the market place (e.g. firms and consumers) know their full interests and the role of marketing research is to facilitate their expression. However, in the relationship marketing field the consensus is drifting from the view that individual actors know their full interest, to the view that it is only by recognising their mutual dependence that the actors can define their distinct interests, and that marketings role is to encourage the recognition of mutuality and the definition of particularity. While, this relational principle has been espoused in the fields of industrial and services marketing, it is not widely accepted in consumer markets mainly because the firm is dealing with many customers who, in many cases, remain anonymous to the firm. However, the assumption that relationship marketing is radically easier between companies or in service contexts than between consumers and their suppliers is open to question.

Recently, Tzokas and Saren (1997) have proposed that relationship marketing is "the process of planning, developing and nurturing a relationship climate that will promote a dialogue between a firm and its customers which aims to imbue an understanding, confidence and respect of each others' capabilities and concerns when enacting their role in the market place and the society" (p.106). A key tenet of this definition is that dialogue among the firm and its customer can bring a higher level of learning about each other. However, dialogue is more than that. As Hazen (1994) puts it "to name ones experience in dialogue and to be heard and responded to by the other is to reflect on that experience and, doing so, actively change the context in which it occurs" (p.398). She approaches dialogue as a "method of inquiry and a process of change" (p.396).

From an organisational management perspective Schein (1993) views dialogue as offering "a way of building a basis for mutual understanding and trust by uncovering the basic cognitive processes that underlie individual and group assumptions" (p.40). From a relationship marketing management perspective we view dialogue as an opportunity for value transformation and an avenue for competitive advantage. By creating unique inter-experiences (Laing et al., 1966) and a new way of "being" in a relationship (Elinor and Gerard, 1998), dialogue transforms perceptions about what constitutes value for both the firm and its customers. The corollary of this, is that relationships henceforth developed with customers become core competencies of the firm which, owing to the uniqueness of the individuals involved, become non-imitable by other firms.

Furthermore, relationship marketing researchers (e.g. Gummesson, 1987,1994) have approached dialogue as a means of appreciating the broader dimensions in which actors from the production and consumption system are associated. Indeed, as Elinor and Gerard (1998) postulate "dialogue moves us beyond the individual to a focus on the larger social and cultural context in which we live? it works to bring integration and wholeness of perspective into the day-to-day decisions we make" (p.14). The latter supports Gummesson (1994) call to view relationships as they develop in the market place and society as a whole and their interdependence. Such an approach allows relationship marketing firms to expand the bases of consumer satisfaction by addressing consumers attributions to value. As Alexander (1997) puts it, relationship management "is not simply about 
gathering more information, but about shaping needs and behaviours to develop mutual advantage" (p.788).

\section{Conclusions and I mplications}

The discussion presented thus far illustrates our observations and thoughts about a number of issues relating to value creation by means of dialogue and collaborative and competitive acts in the consumers own domain. The following points summarise this discussion in a concise, proposition-like form and set the stage for possible theoretical implications and new research direction.

Customer value is a dynamic and transformational higher level construct, which should not be reduced to a low-level operational measurement. Consumers can create value through collaboration and competition in their own domain, just as firms do. Consumers and firms full interests can only be realised through the relationship between them.

Dialogue is the necessary mechanism for the creation of unique inter-experiences and hence, transformational value for both parties. We argue that the propositions above hold a number of implications for both the theory and practice of marketing. To begin with, from a theoretical point of view the case can be made that there is value in attempts to synthesise developments in the fields of consumer research and marketing management. Indeed during the last 30 years, the two fields have developed separately. It would be fair to suggest that consumer researchers have reached a point where they know quite a lot about the behaviour of consumers but increasingly little about how management should make good use of this knowledge. By the same token, marketing management or marketing theory has become more of an organisational behaviour theory with increasingly little relation to its original focal point i.e. the consumers. As a result, our assertion that value, for both the firms and its customers, is created in the combined, yet unique effort, of what is traditionally defined production and consumption outlines how the two systems work synergistically. We expect the same synergy in efforts to integrate insights from consumer research and marketing management. In addition, as the knowledge pool of consumer research is increasingly incorporating advances form fields such as psychology, sociology, anthropology and critical theory, relationship marketing researchers investigating the concept of customer value also should visit a wider range of literature and academic disciplines.

Hunt (1994) argued that although we know a lot about how companies compete in the market place we know little about how they collaborate. He put forward the need for a theory of collaboration among firms. Adding to his call, we suggest the need for a theory of competition and collaboration among consumers. In this paper we have scratched only the surface of what we perceive to be an area of outstanding importance for the further development of the marketing discipline. More research on this issue will allow relationship marketing researcher to reach the customers experiential space and draw useful insights for navigating their organisational policies and practices.

The latter, will become easier if research attention is directed to the ways firms could recognise the value of dialogue with their customers and practice it in the market place. Research efforts in this direction can progress rapidly by borrowing existing insights from the fields of industrial and service marketing. For example, in the industrial marketing field, it is now recognised that communication 
encounters between the firm and its customers are characterized by mutual learning where both parties play an active role in defining the final shape, use and meaning of the product (Biemans, 1992), and therefore, value perceptions for both parties is transformed. Industrial marketing recognises the learning and transformational aspects of these encounters and has devised methods to assist mutual learning. In a similar vein, marketers of consumer products should approach dialogue in these terms. The usefulness of our suggestion can be made clearer if one considers some of the recent technological advances in the field of telecommunications that allow an active interaction between the firm and its customers (e.g. interactive TV, Internet, Call Centers and so on).

Finally, in this paper we have questioned the usefulness of existing measurements of customer value. We would not deny that scores of customer value could assist marketing managers to evaluate their firms performance and identify areas of concern. Yet, in order to take action, we would argue that marketing managers need to reach a different level of insight into the consumer experiential space. This is, they need to address the consumers attributions to their evaluations of the value they receive. This would entail fine-grained research strategies from interpretive sociology (Burrell and Morgan, 1994) such as ethnographic methods (Prus, 1989; Agar, 1990; Schwartzman, 1993). We suggest such approaches since they can take account of the inherently dynamic nature of customer value.

\section{REFERENCES}

- Agar, M. H., (1990), Speaking of Ethnography, Sage University Paper series on

Qualitative Research Methods, Vol.2, SAGE Publications, Newbury Park.

- Alexander, M., (1997), Managing the Boundaries of the Organization, Long Range Planning, 30(5), 787-789.

- Argyris, C. \& Schon, D. (1978), Organizational learning. Reading MA: Addison-Wesley.

- Barnes, J.G., (1994), Close to the Customer: but is it Really a Relationship?, Journal of Marketing Management, 10, 561-570.

- Baudrillard. J. (1996), The System of Objects (Trans. James Benedict), Blackwell Verso.

- Belk, R.W. (1988), Possessions and the extended sense of self, J ournal of Consumer

Research, 15, 139-168.

- Bitner, M.J. (1990) Evaluating Service Encounters: The Effects of Physical Surroundings and Employee Responses, Journal of Marketing, 54, April, pp 69-82

- Bitner, M.J. (1992) Servicescapes: The Impact of Physical Surroundings on Customers

and Employees, Journal of Marketing, 56, April, pp 57-71

- Bourdieu, P. (1984), Distinction: a social critique of the judgement of taste (Trans. R.

Nice), London, Routledge.

- Brown, S. (1995), Postmodern marketing, London, Routledge.

- Brownlie, D. and M. Saren (1992), The Four Ps of the Marketing Concept: Prescriptive,

Polemical, Permanent and Problematical, European J ournal of Marketing, 26, 4, 34-47.

- Burrel, G. and Morgan, G., (1994), Sociological Paradigms and Organisational Analysis,

Ashgate Publishing Ltd., Hants.

- Cronin, J.J. and S.A. Taylor (1992) Measuring Service Quality: A Reexamination and

Extension, J ournal of Marketing, 56, July, 55-68

- Day, R. H. and Wensley, R. (1983), Marketing Theory with a Strategic Orientation,

Journal of Marketing, 47, 79-89.

- De Ruyter, K., M. Wetzels, J. Lemmink and J. Mattson, (1997), The dynamics of the

service delivery process: A value-based approach, International J ournal of Research in Marketing, 14, 231-243.

- Douglas, M. \& Isherwood, B. (1996), The Worlds of Goods: Towards an Anthropology of Consumption, 2nd edition, London, Routledge.

- Elinor, L. and G. Gerard, (1998), Dialogue: Rediscovering the transforming power of conversations, NY., J ohn Wiley \& Sons, Inc.

- Engel, J.F., Blackwell, R.D. \& Miniard, P.W. (1990) Consumer behavior, 6th edition,

Chicago, Dryden Press.

- Flint, D. J., R. B. Woodruf and S. F. Gardial, (1997), Customer value change in Industrial 
Marketing Relationships, Industrial Marketing Management, 26, 163-175.

- Gell, A. (1986), Newcomers to the world of goods: consumption amongst the Muria Gonds, In A. Appadurai (ed.), The Social Life of Things: Commodities in Cultural Perspective, Cambridge MA, University of Cambridge Press.

- Gronroos, C. (1997), Value-driven Relational Marketing: from Products to Resources and Competencies, J ournal of Marketing Management, 13, 407-419.

- Gummesson, E. (1987), The New Marketing: Developing Long Term Interactive

Relationships, Long Range Planning, 20 (4), 10-20.

- Gummesson, E. (1994), Making Relationship Marketing Operational, Service Industry Management, 5(5), 5-20.

- Gummesson, E. (1998), Implementation Requires a Relationship Marketing Paradigm,

Journal of - the Academy of Marketing Science, 26(3), 242-249.

- Hartman, R. S. (1967), The structure of Value, Cabondale, Southern Illinois Press.

- Hazen (1994), A radical humanist perspective of interorganisational relationships, Human Relations, 47, 4, 393-415.

- Heider, J. (1953), The Psychology of Interpersonal Relations, New York: J.Willey \& Sons

- Hirschman, E.C. \& Holbrook, M.B. (1982), The Experiential Aspects of Consumption:

Consumer Fantasies, feelings and fun, Journal of Consumer Research, 9, September, 132-140.

- Hollbrook, M. B., (1994), The Nature of Customer Value, In R.Rust and R.Oliver (eds),

Service Quality, 21-71.

- Holt, D.B. (1995), How Consumers Consume: A Typology of Consumption Practices,

Journal of Consumer Research, 22 (June), 1-16.

- Holt, D.B. (1998), Does Cultural Capital Structure American Consumption? Journal of

Consumer Research, 25 (June).

- Hunt, S. (1994), On Rethinking Marketing : Our Discipline, Our Practice, Our Methods,

European Journal of Marketing, 28(3),13-25.

- Laermans, R. (1993), Learning to Consume: Early Department Stores and the Shaping of

Modern Consumer Culture (1860 - 1914), Theory, Culture and Society, 10, 79-112.

- Laing, R. D., H. Phillipson and A.R. Lee, (1966), Interpersonal Perception, London,

Tavistock Publications.

- Malinowski, B. (1922/1978), Argonauts of the western Pacific: an account of native enterprise and adventure in the archipelagos of Melanesian New Guinea, London, Routledge and Kegan Paul.

- Mattson, J. (1988), Developing an Axiological Method to Measure Company Values,

European J ournal of Marketing, 22(6), 21-35.

- Mattson, J. (1990), Measuring Inherent Product Values, European Journal of Marketing, $24(9), \quad 25-38$.

- Mauss, M. (1966), The gift: forms and functions of exchange in archaic societies, (trans.

I. Cunnison), Cohen-West.

- McKenna, R. (1991), Relationship Marketing ? Successful Strategies for the Age of the

Customer, Addison-Wensley, Reading, MA.

- Normann, R. and R. Ramirez (1993), From Value Chain to Value Constellation: Designing Interactive Strategy, Harvard Business Review, (J uly-August), 65-77.

- Ostergaard, P, Fitchett, J.A. \& Jantzen, C. (1998), On Approapriation and Singularisation: Two consumption Processes, Advances in Consumer Research, XXVI.

- Parasuraman, A., V.A. Zeithaml and L.L. Berry (1985) A Conceptual Model of Service Quality and its Implications for Future Research, Journal of Marketing, 49, 41-50.

- Parasuraman, A., V.A. Zeithaml and L.B. Berry (1988), SERVQUAL: A Multiple-Item Scale for Measuring Consumer Perceptions of Service Quality, J ournal of Retailing, 64, 1, Spring

- Piercy, N. F. (1998), Marketing Implementation; The Implications of Marketing Paradigm Weakness for the Strategy Execution Process, J ournal of the Academy of Marketing

Science, 26(3), 222-236.

- Porter, M.E. (1980) Competitive Strategy, Free Press, New York

- Prus, R. C., (1989), Pursuing Customers : An Ethnography of Marketing Activities, Sage

Library of Social Research 171, Sage Publications, Inc., Newbury Park.

- Ravald, A. and C. Gronroos, (1996), The value concept and relationship marketing,

European Journal of Marketing, 30(2), 19-30.

- Schein, E. H. (1993), On dialogue, culture and organizational learning, Organizational Dymanics, 22(2), 40-52.

- Schwartzman, H. B., (1993), Ethnography in Organizations, Sage University Paper series on Qualitative Research Methods, Vol.27, Newbury Park, SAGE Publications. 
- Shanteau, J. (1992), Competence in experts: the role of task characteristics,

Organisational Behavior and Human Decision Processes, 53, 252-266.

- Sheth, J.N. and A. Parvatiyar, (1995), Relationship Marketing in Consumer Markets:

Antecedents and Consequences, Journal of the Academy of Marketing Science, 23(4), 255-271.

- Sinkula, J.M. (1994), Market information processing and organisational learning, Journal of Marketing, 58, 35-45.

- Spence, M.Y. \& Brucks, M. (1997), The moderating effects of problem characteristics on experts and novices judgments, J ournal of Marketing Research, 34 (May), 233-247.

- Tarde, G. (1890/1962), The Laws of Imitation, Clouchester, MA.

- Tzokas, N. and M. Saren, (1997), Building Relationship Platforms In Consumer Markets:

A Value Chain Approach, J ournal of Strategic Marketing, 5 (2), 105-120.

- Vandermerwe, S. (1996), New Competitive Spaces: J ointly investing in new customer logic, The Columbia Journal of World Business, Winter, 81-101.

- Veblen, T. (1899/1995), The Theory of The Leisure Class: An Economic Study of Institutions, Hammondsworth, Penguin.

- Webster, F.E., (1988), Developing, disseminating and utilising marketing knowledge, J ournal of Marketing, 52 (4), 48-51.

- Wikstrom, S. (1996), Value Creation by Company-Consumer Interaction, Journal of Marketing Management, 12, 359-374.

- Wikstrom, S. and R. Normann (1994), Knowledge and Value-a new perspective on corporate transformation, London, Routledge.

- Williams, H. (1982), Dream worlds: mass consumption in late nineteenth-century France,

Berkeley London, University of California Press.

- Wilson, D.T and Jantrania, S. (1994), Understanding the Value of a Relationship, Asia-

Australia Marketing Journal, 2(1), 55-66.

- Woodruff, R.B. (1997), Customer Value: The Next Source for Competitive Advantage, Journal of the Academy of Marketing Science, 25, 2, 139-153.

- Workman, J.P. Jr. (1993), Marketings limited role in NPD in one computer systems firm, Journal of Marketing Research, 30, 405-421.

- Zeithaml V.A., L.B. Berry and A. Parasuraman (1993) The nature and Determinants of customer Expectations of Service, Journal of the Academy of Marketing Science, 21, 1, 1-12.

Adam Vrechopoulos Department of Information Systems and Computing Uxbridge, Middlesex, UB8 3PH, UK

HELTRUN (Hellenic ELectronic Trading Research UNit) Athens University of Economics \& Business Patission 76, 10434, Athens, Greece

Email: avrehop@aueb.gr 